\title{
Teaching4Learning@UNIPD to promote faculty development at the University of Padua, Italy: the experience of the Agriculture and Veterinary Medicine School
}

\author{
Barbara Cardazzo ${ }^{1}$, Giuseppe Radaelli ${ }^{1}$, Angela Trocino ${ }^{1}$, Lucia Bailoni ${ }^{1}$, Edward \\ Taylor $^{2}$, Monica Fedeli ${ }^{2}$ \\ ${ }^{1}$ Department of Comparative Biomedicine and Food Science, University of Padova, Italy, \\ ${ }^{2}$ Department of Phylosophy, Sociology, Education and Applied Psychology, University of \\ Padova, Italy.
}

\begin{abstract}
Teaching4Learning@UNIPD started in 2016, and it representes the first step for the University of Padua to foster innovative teaching in response to European recommendations. It encourages faculty to experiment with new teaching strategies; involves students and promotes their active participation in educational activities; de-privatizes teaching; and has progressively increased the number of faculty learning communities. It was initiated by faculty who self-selected to participate and who had a significant inclination to enhance their approach to teaching and learning. The School of Agriculture and Veterinary Medicine joined the T4L@UNIPD programme organizing a first level course and is currently participating in a second level course promoted by UNIPD and aimed at training 30 selected professors (among them, 9 from the AMV School) in order to promote teaching and innovation within their Departments. The study of several differents strategies, tools and actions were included in the course and their application in teaching are now in progress.
\end{abstract}

Keywords: Faculty promotion project;Active learning; Learning community; new teaching strategies. 


\section{Introduction}

The Teaching4Learning@UNIPD (T4L@UNIPD) programme began in the 2016/2017 academic year, as a consequence of findings of a national funded project called Employability \& Competences (Fedeli et. al. 2017, Fedeli, 2016), with the aim of promoting teaching innovation at the University of Padua, Italy. It represented the first step for the University to foster innovative teaching in response to European recommendations (European Commission 2011; 2013). Each of the departments involved implemented a faculty development programme based on the needs of its instructors. The goal was to introduce interactive teaching practices reflecting a model or an "Italian way" based on the contemporary research of effective practices for student teaching and learning. The aim is to develop a mix methods research design (Creamer, 2018) by listening to the students' voices, better understanding their thoughts on teaching and enhancing ways in which faculty teach. Instructors experiment and discover together new teaching strategies to involve students and encourage them to participate actively in educational activities; slowly de-privatizing their teaching (Adam \& Mix, 2014); and progressively increasing the number of faculty learning communities through the involvement of other interested colleagues. All the instructors involved were selfselected, strongly interested and motivated to participate, with a significant inclination to share their teaching experience. As this programme was implemented, it became apparent that equal attention had to be given to organizational change and to the training of individual faculty innovative teaching practices. This meant putting teaching and learning at the centre of reflective discussions and creating a culture for change. Since 2016, more than 400 faculty members of UNIPD have participated in the faculty development programme. Anecdotal responses by faculty on the training were collected and a constant among these responses has been that most faculty found the training impactful. However, despite the enthusiasm for the programme, there was also a general sense that new teaching practices would be difficult to implement, particularly with regard to the institutional emphasis on covering content, i.e. a passive transmission teaching model, and on formal examinations. The challenge of supporting faculty in this process involves identifying the related implications of fostering innovative teaching and learning and the role the organization/institutional culture plays in the development process. Historically, the Italian higher education context is characterized by minimum attention to teachers' teaching activities, and by exceptionally high attention to research activities, which reflects on how career progression is implemented. Furthermore, it becomes important, in this context, to underline how the long tradition of lecturing as the preponderant didactic form and the lack of attention to the interaction and the involvement of students has made the promotion of didactic innovation very difficult. Especially within a university that is almost 800 years old such as UNIPD. 


\section{T4L@UNIPD: the experience of the Agriculture and Veterinary Medicine School}

The University of Padua is organized in departments, mainly involved in research activities, and schools which coordinate the teaching activities. The departments of the University of Padua are 32, the schools are 8 , while the total number of professors is 2.200 for a number of student of about 60.000 .

Among the 8 schools, one is located in Agripolis Campus and is the School of Agricultural Science and Veterinary Medicine (AMV). The School includes 208 professors from 4 different Departiments and gather 3.500 students from 18 bachelor and master degrees.

The AMV School joined the T4L@UNIPD programme organizing a residential weekend course of innovative teaching, where the 37 self-selected professors involved were strongly interested and motivated to participate, with a significant inclination to share their teaching experience. The proposed programme has been described above (Introduction) and aims at beginning a faculty learning community. The residential weekend, held in a place located far from the university campus, made possible a greater sharing of objectives favoring constructive interaction and socialization between participants.

The programme was significantly appreciated as reported in Fig. 1

A

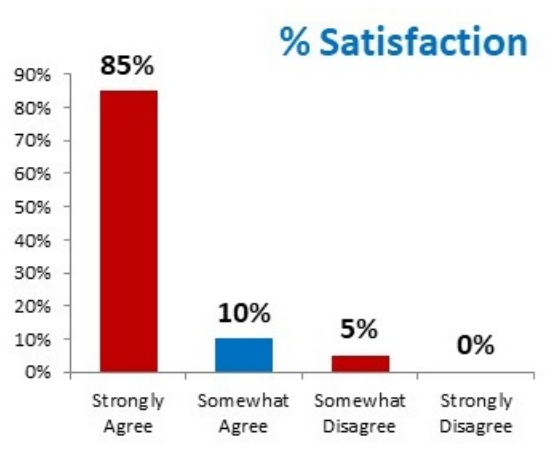

B

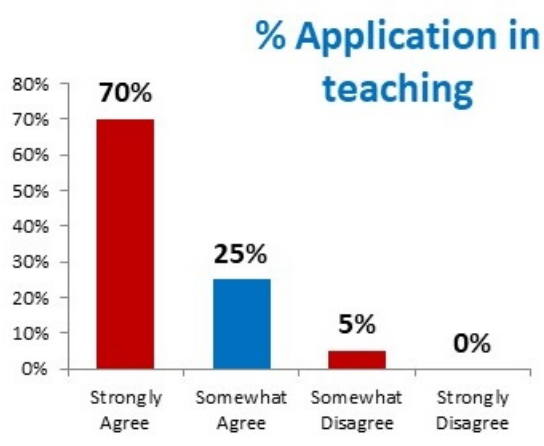

Figure 1. Result of the survey among participants to AMV school T4L@UNIPD programme

After this experience, the AMV School joined a second level experience promoted by UNIPD and aimed at training 30 selected professors (among them, 9 from the AMV School) in order to improve teaching and innovation within their Departments, including reflection 
activities, training and sharing of successful teaching practices. The final purpose of the course is to form a community of Change Agents who will assist and help teachers in their activities.

\section{Future implications for innovative teaching in AMV School and final reflections}

The satisfaction index compiled at the end of the first course is encouraging and shows an interest and availability of the professors belonging to AMV School to be part of this change process under the supervision of the Change Agents.

The Change Agents promote the development of different activities with the aim to introduce change in teaching. In particular, they are developing: sharing of ideas and strategies to promote peer observation among colleagues (mini-teach and observation in the classroom), deepening of methods and techniques of active-learning (group activities, workcafè, application of online tools for interactive activity and feedback such as: Kahoot, Top Hat etc.), the promotion of self-directed learning processes, the elaboration of a syllabus according to constructive alignment.

In conclusion, the AMV School through the Change Agents intends to develop a learning community which recognizes a full role to teaching within the University missions, aims at collectivizing teaching experience to gain awareness about different personal potentials and, last but not least, intend to facilitate student learning processes by their active participation in the teaching activity.

The AMV School throughout the activity of the Change Agents are developing methods useful to monitor the impact of the innovative teaching programme on students by evaluating assessment questionnaire and performance of final exams.

\section{References}

Adams S.R. \& Mix E.K. 2014, Taking the lead in Faculty Development: Teacher Educators Changing the Culture of University Faculty Development through Collaboration, AILACTE, 11: 37-56.

Creamer, E.G. (2018). An introduction to fully integrated mixed methods research. Thausend Oaks, CA: SAGE.

European Commission (2011). Supporting growth and jobs - an agenda for the modernisation of Europe's higher education systems. Retrieved from http://ec.europa.eu/education/library/policy/modernisation_en.pdf

European Commission (2013). Report to the European Commission on improving the quality of teaching and learning in Europe's higher education institutions. Luxembourg: Publications Office of the European Union. 
Fedeli, M. (2016). Coinvolgere gli studenti nelle pratiche didattiche: potere, dialogo e partecipazione. In M. Fedeli, V. Grion, \& D. Frison (eds), Coinvolgere per apprendere. Metodi e tecniche partecipative per la formazione (pp.113-142). Lecce: Pensa Multimedia.

Fedeli, M.; Frison, D. \& Grion, V. (2017). Fostering learner-centered teaching in higher education. In: Boffo, V.; Fedeli, M.; Lo Presti, F.; Melacarne, C. \& Vianello, M.; (eds.) Teaching and Learning for employability. New strategies in higher education (pp.89115). Milan, Turin, IT: Pearson Italia. 